\title{
Real-time Screening of Foods Using Repetitive Element PCR Reveals a DNA Marker Characteristic for Enterotoxigenic Bacillus Species
}

\section{Breanna R. Brenneman', Kyla L. Adamson², Matthew R. Beer', Yenling $H_{a^{4}}$, Kiev S. Gracias ${ }^{5}$, Chelsea M. Priest ${ }^{6}$, Erika N. Biernbaum? , and John L. McKillip*}

Department of Biology, Ball State University, Muncie, IN 47306

${ }^{1}$ Current address: University of Virginia, Charlottesville, VA USA

${ }^{2}$ Current address: Elanco, Clinton, IN USA

${ }^{3}$ Current address: Cooper Genomics, Houston, TX USA

${ }^{4} \mathrm{CDC}$ Foundation, Indianapolis, IN USA

${ }^{5}$ Department of Biology, Oakland City University, Oakland City, IN 47660

${ }^{6}$ Current address: Community Hospital, Anderson, IN USA

${ }^{7}$ Current address: Food Safety and Enteric Pathogens Research Unit, National Animal Disease Center, Agricultural Research Service, U.S. Department of Agriculture, Ames, IA, USA 
Manuscript received 1 September 2020; accepted 9 December, 2020

Key words: Bacillus, enterotoxigenic, detection, rep-PCR, DNA fingerprinting

\section{Abstract}

Bacillus cereus is traditionally thought to be the only member of its genus accepted as a pathogen in foods like grains, fruits, vegetables, and milk due to the presence of the nonhemolytic (Nhe) operon. However, many other Bacillus spp. may also harbor the Nhe operon and be pathogenic, including not just food-associated gastrointestinal toxicoinfections, but human endophthalmitis as well. Real-time PCR targeted the $n$ heA gene in 37 samples obtained from food, soil, and reference cultures by analyzing the standard deviations of melt peaks. Repetitive element PCR was used to compare the banding patterns of each sample against B. cereus ATCC 14579 and three B. thuringiensis strains to "fingerprint" each isolate. Of the original 43 isolated tested, 37 were Gram-positive rods. The remaining six samples were Gram-positive cocci. Twenty-five of the 37 Gram-positive Bacillus spp. were $n$ heA positive, while twelve were negative. Many of the nheA positive strains were species not previously known to contain Nhe and were capable of causing gastroenteritis in consumers. 


\section{Introduction}

Bacillus spp. are Gram-positive endospore-forming rods ubiquitous in soil worldwide and are primarily aerobic to facultatively anaerobic saprophytes (3). Over 148 distinct Bacillus species have been described. This large number of individual species reflects a high degree of genetic diversity. Taxonomical identification of species within the Bacillus genus has changed over time as differentiation methods have improved (17). Currently, Bacillus species are divided into two groups - the $B$. subtilis and $B$. cereus divisions. The $B$. cereus group includes $B$. cereus, $B$. mycoides, $B$. anthracis, $B$. thuringiensis, and $B$. weihenstephanensis. These species are also grouped under the name B. cereus sensu lato (51). Phylogenetically, B. cereus is quite closely related to the entomopathogen $B$. thuringiensis and the human pathogen $B$. anthracis, a fact that has led to vigorous discussion on shared virulence properties, DNA sequence conservation among strains, and prevalence in the environment $(19,39$, 48). Along with $B$. weihenstephanensis, these species constitute a single genetic subgroup, a rather arbitrary classification designation that brings into question how a species is even defined in this family of bacteria. For example, it seems clear that at least for many Bacillaceae other than B. cereus, presence and expression of enterotoxin genes is not uncommon $(7,11$, $18,20)$; nor is it atypical to identify strains of $B$. cereus lacking detectable enterotoxin genes $(5,48)$. Moreover, $B$. cereus may harbor virulence genes on plasmids more commonly associated with $B$. anthracis (49). Many pathogenic strains of Bacillus spp. are primary isolates from clinical, food, and environmental sources. Naturally, many published studies on the $B$. cereus group mention the difficulty in selecting features for reliable identification of these species. The involvement of species in the $B$. cereus group in foodborne illness, as a leading cause of ocular infections (endophthalmitis), and as an indicator of water quality $(4,25)$, begs the question of how such a closely related set of species and strains could manifest itself so differently in varied environments. Accordingly, a reassessment of identification strategies is in order as even more reports appear in the literature of Bacillus spp. involvement in novel ecological niches.

The search for a reliable DNA-based typing approach for Bacillaceae has explored several technologies in recent

Table 1.

\begin{tabular}{|cc|}
\hline Lesaffre Yeast & Smuckers French Vanilla \\
\hline & \\
\hline Seasoning & Snacks \\
\hline Basil & Beef Taco from Taco Bell \\
\hline Oregano & Food Club Quick Oats \\
\hline Mustard & Ann's House Healthy Energy Blend Nuts \\
\hline Nutmeg & Kraft Jet-Puffed Marshmallows \\
\hline Paprika & Dannon Yogurt \\
\hline Milk & Coffee Creamer \\
\hline Parmalat 2\% Reduced Fat Milk & Coffee Mate \\
\hline Mix N' Drink Skim Milk & Wholesome Farms \\
\hline Great Value Evaporated Milk & Great Value \\
\hline Myenberg Vitamin D Goat Milk & Glenview Farms \\
\hline Carnation Evaporated Milk & Flavor Right Half and Half \\
\hline Prairie Farms & \\
\hline & \\
\hline
\end{tabular}

Table 1: Foods screened for the presence of Bacillus spp. by food type as described in Materials and Methods. 
years, including repetitive element PCR (rep-PCR) (34), next generation sequencing (NGS) of whole genomes to identify polymorphic regions (12), and multilocus sequence typing (MLST) $(6,21,22)$, which relies on the PCRbased amplification of 400-600bp internal fragments of housekeeping genes. However, these conserved gene targets are frequently not adequate to effectively resolve Bacillus species or strains for identification. Clearly, a repertoire of both phenotypic and novel genotypic-based methods must be utilized for the ever-increasing number of strains appearing in the literature. This trend reflects a growing interest in this group of bacteria (4). The objective and hypothesis of this research is that one may develop a genotypic screening method to reliably detect enterotoxigenic Bacillus spp. from contaminated food without the need for culture-based methods. Use of DNA typing/fingerprinting compared to positive control enterotoxigenic (Nhe-producing) Bacillus, we show the potential in rep-PCR as a rapid and highthroughput screening tool for a variety of contaminated foods.

\section{MATERIALS AND METHODS}

Bacillus spp. isolation from soil and food.

Using a previously described method (46), soil was collected (at 4-inch depths) from multiple locations around the Ball State University campus in Muncie, IN. A total of 41 varieties of flavoring/ powder, seasonings, milk, coffee creamers, cheese, snacks, spreads, and drink additives were obtained at local retailers in order to isolate Bacillus spp. from these naturally contaminated foods (Table 1 ). Each sample (5g) was added to $100 \mathrm{~mL}$ of brain heart infusion broth (BHIB; BD Diagnostic Systems, Franklin Lakes, NJ). After mixing, the solution was incubated at $32^{\circ} \mathrm{C}$ while shaking at $160 \mathrm{RPM}$ for $72 \mathrm{~h}$. Samples were heat-treated at $80^{\circ} \mathrm{C}$ for $30 \mathrm{~min}$ on a hot plate using a water jacketed vessel and constant shaking, after which the suspension $(1 \mathrm{~mL})$ was pipetted onto quadruplicate tryptic soy agar (TSA; Alpha Biosciences, Baltimore, MD) plates and incubated overnight at $37^{\circ} \mathrm{C}$. Streak plates were performed from initial growth and incubated at $37^{\circ} \mathrm{C}$ overnight to obtain pure cultures, confirmed by Gram and endospore staining. Reference strains (Table 2) were obtained from Presque Isle Cultures (Erie, PA USA) and Dr. James Mitchell (Ball State University, Muncie, IN) and subcultured

Table 2.

\begin{tabular}{|c|c|c|}
\hline Strain & Identifying Code & Source \\
\hline B. subtilis globigii & 6201 & Presque Isle Cultures \\
\hline $\begin{array}{c}\text { B. stearothermophlus } \\
\text { Goobacillus stearothormophilus }\end{array}$ & $\begin{array}{l}627 \\
627 \mathrm{~A}\end{array}$ & $\begin{array}{l}\text { Presque Isle Cultures } \\
\text { Presque Isle Cultures }\end{array}$ \\
\hline $\begin{array}{l}\text { B. sphaericus } \\
\text { B. megaterium }\end{array}$ & $\begin{array}{l}633 \\
616\end{array}$ & $\begin{array}{l}\text { Presque Isle Cultures } \\
\text { Presque Isle Cultures }\end{array}$ \\
\hline $\begin{array}{l}\text { B. macercuns } \\
\text { B. pumulis }\end{array}$ & $\begin{array}{c}626 \\
6222\end{array}$ & $\begin{array}{l}\text { Presque Isle Culluies } \\
\text { Presque Isle Cultures }\end{array}$ \\
\hline B. brevts & 630 & Presque Isle Cultures \\
\hline$B$ polymy $x \Omega$ & 625 & Presgule Isle Cultures \\
\hline B. cougulans & 6221 & Presque Isle Cultures \\
\hline$B$ circulons & 62.8 & Presgule Isle Cultures \\
\hline B. subtilis & 620 & Presque Isle Cultures \\
\hline B. laterosporos & 629 & Presque Isle Cultures \\
\hline B. cereus & 14579 & $\mathrm{ATCC}$ \\
\hline B. thuringiensis kurstaki HDI & 33679 & Dr. James Mitchell \\
\hline B. thw ingiensis japanensis $B 23$ & T23001 & Dr. James Mitchell \\
\hline B. thuringiensis isrcelensis & 114001 & Dr. James Mitchell \\
\hline
\end{tabular}

Table 2: Bacillus reference strains used in this study. 
onto TSA slants. All cultures were refrigerated at $4^{\circ} \mathrm{C}$ until DNA extraction and real-time PCR analysis.

\section{DNA Extraction.}

Each isolate, including reference strains, was separately cultured in tryptic soy broth (TSB, Weber Scientific, Hamilton, NJ USA) grown aerobically by shaking for $24 \mathrm{~h}$ as previously described (31). Bacteria were pelleted by centrifugation at 9,000 $\mathrm{xg}$ for $3 \mathrm{~min}$ at $4^{\circ} \mathrm{C}$ and the pellets were resuspended in 300 $\mu \mathrm{l}$ TE buffer (Amresco, Solon, $\mathrm{OH}$ ) containing $30 \mu \mathrm{l}$ of $10 \%$ SDS (Promega, Madison, WI), and $20 \mu \mathrm{l}$ of $20 \mathrm{mg} / \mathrm{mL}$ Proteinase K (Ambion, Austin, TX). Following a $37^{\circ} \mathrm{C} 30 \mathrm{~min}$. incubation, an equal volume of phenol:chloroform:isoamyl alcohol (25:24:1) solution (Amresco) was added, vortexed, and centrifuged for $10 \mathrm{~min}$. at $10,000 \mathrm{xg}$ and $4^{\circ} \mathrm{C}$. The aqueous phase was carefully transferred into clean microcentrifuge tubes and mixed with 0.1 volume of cold $3 \mathrm{M}$ sodium acetate (Fisher Scientific, Pittsburgh, PA) and one volume of cold 95\% isopropanol (Greenfield Ethanol Co., Brookfield, $\mathrm{CT})$. The microcentrifuge tubes were inverted to mix and centrifuged for $30 \mathrm{~min}$ at $16,000 \mathrm{xg}$ at $4^{\circ} \mathrm{C}$. The supernatant was discarded, and the dried DNA pellets were quantified spectrophotometrically to assess yield and purity.

\section{Uniplex PCR.}

All DNA samples were normalized to a concentration of $1 \mu \mathrm{g} /$ $\mu \mathrm{L}$ in sterile water. All reactions were performed in triplicate. Real-time PCR was used initially to target the nheA gene (32). Primer sequences used for this and other experiments are shown in Table 3.

PCR was performed as previously described (18) with minor modifications. The annealing temperature was changed from $55^{\circ} \mathrm{C}$ to $52^{\circ} \mathrm{C}$ to better support annealing of the $n h e A F$ primer to template DNA, and a melting curve was used to resolve and validate amplicon identity. Each PCR reaction consisted of $1 \mathrm{X}$ iQ Sybr Green Supermix (Bio Rad, Hercules, CA), 100 pmol nheAF and $n h e A R$ primers (Integrated DNA Technologies, Coralville, IA), and $0.5 \mu \mathrm{g}$ of template DNA. Nuclease-free water (Promega) was added for a final volume of $25 \mu \mathrm{L}$ in $0.2 \mathrm{~mL}$ PCR tubes (Corbett Research, Concord, NSW). A positive control was included in each set of reactions, consisting of template DNA from B. cereus ATCC 14579, (American Type Culture Collection, Manassas, VA), previously shown to harbor the nhe $A B C$ operon (41).

PCR reactions were performed in a Rotor Gene RG-3000 thermocycler (Corbett Research) using an initial $94^{\circ} \mathrm{C}$ 120 s denaturation step followed by 35 cycles of $94^{\circ} \mathrm{C}$ for $20 \mathrm{~s}, 52^{\circ} \mathrm{C}$ for $60 \mathrm{~s}$, and $72^{\circ} \mathrm{C}$ for $60 \mathrm{~s}$. A final $72^{\circ} \mathrm{C} 6 \mathrm{~min}$. extension step preceded melting curve analysis $\left(40^{\circ} \mathrm{C}\right.$ to $95^{\circ} \mathrm{C}$ in $0.7^{\circ} \mathrm{C}$ per second increments). Amplicon melting peaks were plotted using Rotor Gene 6 software and melt peak data were exported into Microsoft Excel for analysis. Only melt peaks within 1 standard deviation of the average melt peak of positive control B. cereus ATCC 14579 were considered as positive for the presence of nheA.

\section{Rep-PCR.}

DNA templates from all strains analyzed (Table 1) were subjected to repetitive element- PCR (rep-PCR) using a Diversilab kit (Bacterial Barcodes, Athens, GA) specific for fingerprinting Bacillus spp. DNA of each sample previously isolated for real-time PCR was re-standardized to $50 \mathrm{ng} /$ $\mu$ l. Primers for repetitive elements within Bacillaceae were included in the Diversilab kit and are shown in Table 3 (24).

All reactions were completed in triplicate and consisted of $18 \mu \mathrm{l}$ rep-PCR MM1 buffer, $2.5 \mu \mathrm{l}$ of GeneAmp ${ }^{\oplus} 10 \mathrm{X}$ PCR Buffer, $2.0 \mu \mathrm{l}$ of primer mix, and $0.5 \mu \mathrm{l}$ of Taq DNA Polymerase (5 PRIME, Gaithersburg, MD) and 100 ng of template DNA. Positive kit controls were included with each set of replicates, as were no template controls (NTC). All reactions were performed using a Rotor Gene instrument and consisted of an initial $94^{\circ} \mathrm{C} 2 \mathrm{~min}$. denaturation followed by 35 cycles of $94^{\circ} \mathrm{C}$ for $30 \mathrm{~s}, 55^{\circ} \mathrm{C}$ for $30 \mathrm{~s}$, and $70^{\circ} \mathrm{C}$ for 90s. Following a final extension step for $3 \mathrm{~min}$ at $70^{\circ} \mathrm{C}$, a subset of reactions was subjected to melting curve analysis as described earlier, while others were analyzed using agarose gel electrophoresis. For the latter samples, $5 \mu$ l of each PCR product was loaded into a $1.5 \%(\mathrm{w} / \mathrm{v})$ agarose gel (BioExpress, Kaysville, UT) containing $0.625 \mu \mathrm{g} / \mu \mathrm{l}$ ethidium bromide 
(Invitrogen, Carlsbad, CA) (43) and the gel electrophoresed for $1.5 \mathrm{~h}$ at $70 \mathrm{~V}$ (constant). The gel was visualized on a Gel Doc XR (Bio-Rad, Hercules, CA) using UV light. The resulting banding patterns were recorded in Microsoft Excel as a virtual gel (Table 4). Banding patterns of $n h e A$ positive and $n h e A$ negative were compared against the $B$. cereus reference strain and three $B$. thuringiensis strains, representing additional members of the $B$. cereus genetic subgroup. Sample bands identical to each reference strain (B. cereus, $B$. thuringiensis var. kurstaki, B. thuringiensis var. japanensis, and $B$. thuringiensis var. israelensis) were divided by the number of total bands in each reference strain. The resulting number was multiplied by 100 to determine the percent each sample was identical to $B$. cereus, $B$. thuringiensis var. kurstaki, $B$. thuringiensis var. japanensis, and $B$. thuringiensis var. israelensis.

\section{Sequencing of diagnostic rep-PCR product.}

The 1,230bp diagnostic band (11) earlier found to be unique to enterotoxigenic Bacillus spp. was identified in real-time melting curve plots of B. cereus ATCC 14579 and other strains.

\section{RESULTS}

\section{Samples}

Excluding reference microbes purchased from Presque Isle Cultures, a total of 45 food and soil samples were screened for the presence of Bacillus spp. Of these, 21 isolates (48.9\%) were found to contain no detectable Bacillaceae. Twenty isolates (44.4\%) were Gram-positive, spore-forming rods after heat-treatment and subsequent streak-plating on TSA. These included: basil seasoning, nutmeg seasoning, Tazo tea powder, a beef taco from Taco Bell, Lesaffre Yeast, Prairie Farms Whole Milk, Food Club Quick Oats, Ann's House Healthy Energy Blend Nuts, Peter Pan Peanut Butter, Great Value Peanut Butter, Dannon Yogurt, Chevre Fresh Goat Cheese, Saputo Stella Gorgonzola Cheese, Black Creek Extra Sharp Cheddar Cheese, Pilgrim's Choice Blue Stilton Cheese, Cooper Science Building Soil, Lucina Building Soil, Christy Woods Soil, and Ball Gymnasium Soil. An additional six isolates, three of which were isolated from Jiffy Corn Muffin Mix, were Grampositive cocci. Aside from Jiffy Corn Muffin Mix, Grampositive cocci were isolated from mustard seasoning and Mix n’ Drink Powdered Skim Milk. These Gram-positive cocci accounted for a total of $6.7 \%$ of the entire sample pool.

Seventeen Bacillus spp. reference strains were purchased from Presque Isle Cultures for subsequent real-time PCR analysis. Overall, a total of 37 samples were either pure-type cultures or Gram-positive rods that were subsequently subjected to DNA extraction in preparation for real-time and rep-PCR.

\section{Real-time PCR}

B. cereus ATCC 14579 was used as a positive control to test for the presence of $n h e A$ and had an average melt peak of

Table 3.

\begin{tabular}{|c|c|c|c|c|c|c|}
\hline $\boldsymbol{n} \boldsymbol{h} \boldsymbol{e} \boldsymbol{A}$ & Primer Sequence $\mathbf{5}^{\prime} \rightarrow \mathbf{3}^{\prime}$ & Position & $\begin{array}{c}\text { Accession } \\
\#\end{array}$ & Ref & $\mathbf{T}_{\mathbf{m}}$ & $\mathbf{G} / \mathbf{C}$ \\
\hline F & TACGCTAAGGAGGGGCA & $\begin{array}{c}344-360 \\
\boldsymbol{1}\end{array}$ & Y19005 & 9 & $55.5^{\circ} \mathrm{C}$ & $58.80 \%$ \\
\hline R & GTTTTTATTGCTTCATCGGCT & $\begin{array}{c}843-823 \\
\leftarrow\end{array}$ & - & - & $51.8^{\circ} \mathrm{C}$ & $38.10 \%$ \\
\hline Direction & Primer Sequence 5' $\rightarrow \mathbf{3}^{\prime}$ & $\begin{array}{c}\text { Primer } \\
\text { Name }\end{array}$ & - & Ref & $\mathbf{T}_{\mathbf{m}}$ & $\mathbf{G} / \mathbf{C}$ \\
\hline F & ICG ICT TAT CIG GCC TAC & REP 2-I & - & 15 & $57.5^{\circ} \mathrm{C}$ & $50 \%$ \\
\hline R & III ICG ICG ICA TCI GGC & REP 1R-I & - & 15 & $68.3^{\circ} \mathrm{C}$ & $50 \%$ \\
\hline
\end{tabular}

Table 3: Primer sequences, melting temperatures, and guanine and cytosine content for the $n h e A$ gene used in uniplex PCR and repetitive element (rep-PCR) palindromic sequences in Bacillus spp. 
$81.96^{\circ} \mathrm{C}$ over three runs. As shown in Table 5, fourteen test samples $(37.84 \%=$ green highlighted $)$ were consistently within 1 standard deviation (SD) of the positive control over three separate real- time PCR runs (SD determined using SigmaStat for Windows). Standard deviations of samples positive all of three replications for $n h e A$ are included in Table 6, part B. These samples included reference strains $B$. macerans, B. brevis, B. cereus, B. thuringiensis var. kurstaki, $B$ thuringiensis var. japanensis, and $B$. thuringiensis var. israelensis. Food samples consistently within one SD of the positive control originated from Prairie Farms Whole Milk, Ball Gymnasium soil, Lucina Hall soil, Cooper Science soil, Christy Woods soil, basil seasoning powder, "Clean" Peter Pan Peanut Butter, and Great Value Peanut Butter. Five samples $(13.51 \%$ = yellow highlighted had two melt peaks within 1 $\mathrm{SD}$ of the positive control strain. These included the pure strain B. laterosporos and food samples from a beef soft taco from Taco Bell, nutmeg powder, Chevre Fresh Goat Cheese, and Saputo Stella Gorgonzola Cheese.

Table 4.

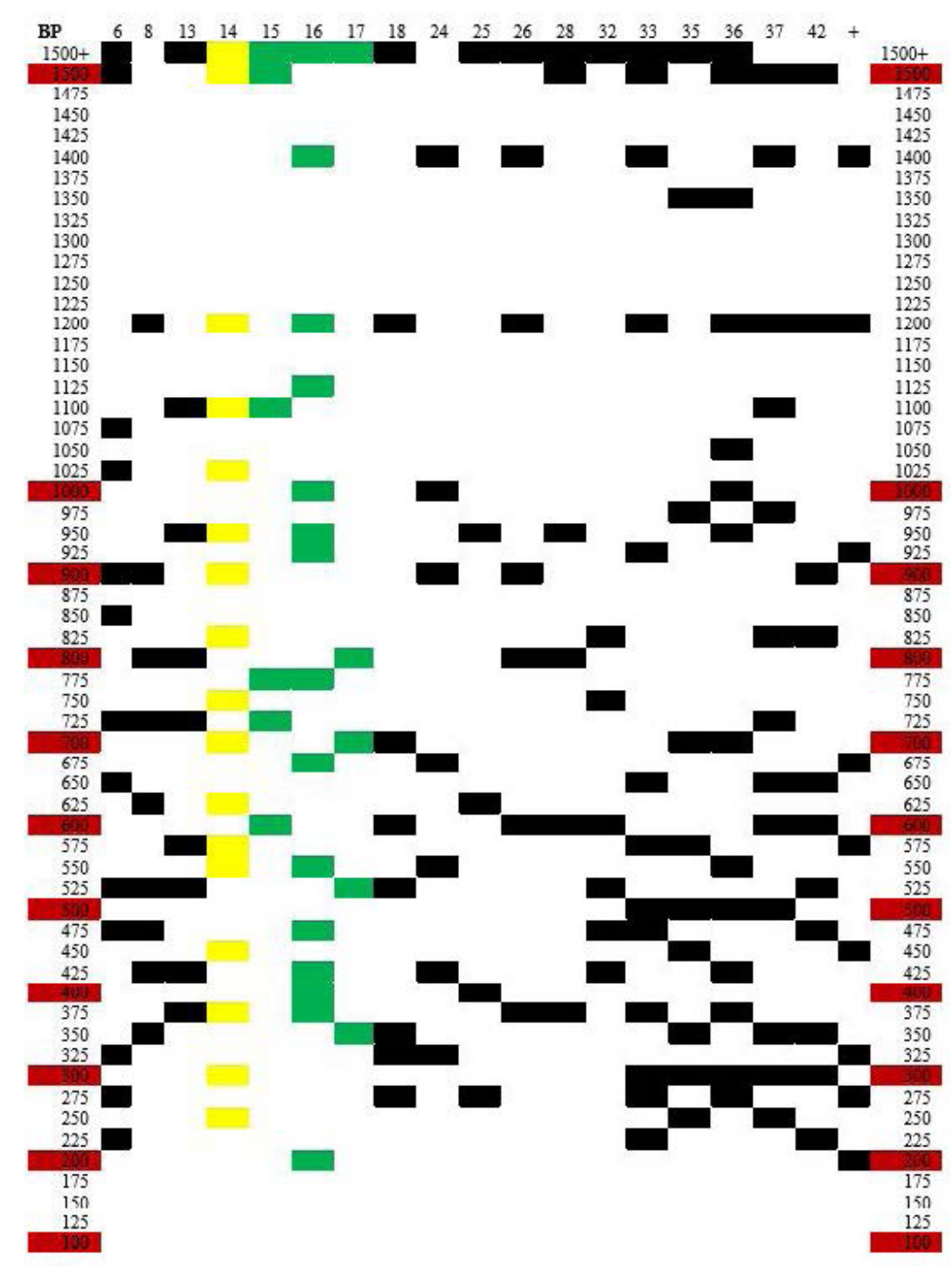

Table 4: Banding patterns of all nheA positive samples, excluding samples 9, 10, 22, 27, 31, 39, and 43. Red cells represent the length in base pairs of each DNA ladder band. Yellow cells represent the column of positive control $B$. cereus ATCC 14579. Green cells represent banding of B. thuringiensis var. kurstaki (\#15), B. thuringiensis var. japanensis (\#16), and B. thuringiensis var. israelensis (\#17). 
Table 5.

\begin{tabular}{|c|c|c|c|}
\hline \# & Sample & \# & Sample \\
\hline 1 & B. subtilis giobigit & 23 & Jiffy Cornbread Cream Colony \\
\hline 2 & B. stearothermapinitus & 24 & Ball Gym Soil \\
\hline 3 & Geobacillus stearothermophitus & 25 & Lucina Building Soil \\
\hline 4 & B. s2gezzows & 26 & Basii Seasoning Powder \\
\hline 5 & B. megaterizon & 27 & Taco Bell Soft Beef Taco \\
\hline 6 & B. macerans & 28 & Cooper Science Soil \\
\hline 7 & B. parmutis & 29 & Mustard Seasoning Powder \\
\hline 8 & B. brevis & 30 & Jiffy Cornbread Translucent Colony \\
\hline 9 & B. polymyxa & 31 & Nutmeg Powder Seasoning \\
\hline 10 & B. coagulans & 32 & Christy Woods Soil \\
\hline 11 & B. circulans & 33 & Chevre Fresh Goat Cheese \\
\hline 12 & B. subtilis & 34 & Black Creek Sharp Cheddar Cheese \\
\hline 13 & B. laterosporos & 35 & Saputo Stella Gorgonzola Cheese \\
\hline 14 & B. cereus & 36 & Pilgrim's Choice Blue Stilton Cheese \\
\hline 15 & B. thuringiensis kurstaki & 37 & "Clean" Peter Pan Peanut Butter \\
\hline 16 & B. thuringiensis japanensis & 38 & Tazo Tea Powder \\
\hline 17 & $B$. thuringiensis israelensis & 39 & Ann's House Energy Blend Nuts \\
\hline 18 & Prairie Farms Whole Milk & 40 & Darinon Yogurt \\
\hline 19 & Jiffy Cornbread Yellow Colony & 41 & Lesaffre Yeast Isolate \\
\hline 20 & Mix $N^{\prime}$ Drink Powdered Milk & 42 & Great Value Peanut Butter \\
\hline 21 & Nesquick & 43 & Salmonella-Contaminated Peter Pan Peanut Butter \\
\hline 22 & Food Club Quick Oats & & \\
\hline & \multirow{2}{*}{\multicolumn{3}{|c|}{$=3$ of 3 melt peaks within $1^{\circ} \mathrm{C}$ of $B$. cereus control $\left(82^{\circ} \mathrm{C}\right)$ melt peak }} \\
\hline & & & \\
\hline & \multicolumn{3}{|c|}{$=2$ of 3 melt peaks within $1^{\circ} \mathrm{C}$ of $B$. cereus control $\left(82^{\circ} \mathrm{C}\right)$ melt peak } \\
\hline & \multicolumn{3}{|c|}{$=1$ of 3 melt peaks within $1^{\circ} \mathrm{C}$ of $B$. cereus control $\left(82^{\circ} \mathrm{C}\right)$ melt peak } \\
\hline & \multirow{2}{*}{\multicolumn{3}{|c|}{$\begin{array}{c}=0 \text { of } 3 \text { melt peaks within } 1^{\circ} \mathrm{C} \text { of } B \text {. cereus control }\left(82^{\circ} \mathrm{C}\right) \text { melt peak } \\
=\text { Not Gram-positive rods, but isolated after heat-treatment }\end{array}$}} \\
\hline & & & \\
\hline
\end{tabular}

Table 5: Samples were positive or negative for the presence of $n h e A 3 / 3,2 / 3,1 / 3$, or $0 / 3$ times. Green samples indicate positive detection of nheA in real-time PCR over three separate runs. Yellow samples indicate nheA positive samples in two of three real-time PCR runs. Orange samples indicate $n h e A$ positive samples in one of three real-time PCR runs. Red samples indicate negative $n h e A$ detection in real-time PCR.

Six samples $(16.22 \%=$ orange highlighted $)$ had one melt peak within 1 SD of the positive control train. These included pure strains $B$. polymyxa and B. coagulans. In addition, food samples with only 1 of 3 melt peaks consistent with $B$. cereus positive control were from Food Club Quick Oats, Pilgrim's Choice Blue Stilton Cheese, Ann's House Energy Blend Nuts, and a jar of Peter Pan Peanut Butter involved in a food recall that may have contained Salmonella.

Twelve of the 37 samples (32.43\% = red highlighted) had either no melt peaks or melt peaks greater or less than one SD of the positive control strain. These included: pure strains B. subtilis globigii, B. stearothermophilus, Geobacillus stearothermophilus, B. spaericus, B. megaterium, G. pumulis, B. circulans, and B. subtilis. Foods negative for nheA included
Black Creek Extra Sharp Cheddar, Tazo Tea powder, Dannon Yogurt, and Lesaffre Yeast.

As shown in Table 6, part A, there were 4 of 16 food samples that tested positive for $n h e A$ for three melt peaks. Additionally, 4 food samples displayed two positive melt peaks, while 4 more displayed one melt peak. Four food samples displayed zero melt peaks. All soil samples were positive for $n h e A$ with three melt peaks. Six reference strains displayed three positive melt peaks for $n$ heA, while only one strain had two melt peaks consistent with the positive control. Two strains had one melt peak in line with the positive control, while 8 strains were completely negative for the presence of nheA. 
After real-time PCR, SD were calculated for sample melt peaks to compare against B. cereus ATCC 14579 . Samples 6, $8,14,15,16,17,18,24,25,26,28,32,37$, and 42 resulted in standard deviations $<1$ when compared against the $82^{\circ} \mathrm{C}$ average positive control melt peak. Any sample with a $\mathrm{SD}<$ 1 indicated a positive detection for the nheA gene. Data are shown in Table 6, part B.

\section{Rep-PCR}

Repetitive element PCR was utilized on $B$. cereus ATCC 14579, which was labeled as sample 14 for real-time and rep-PCR. This strain was subsequently used as the standard against which all other nheA positive samples in rep-PCR were compared. Sample 14 displayed 16 bands within the

Table 6.

A.

\begin{tabular}{|c|c|c|c|c|c|c|}
\hline \# $\boldsymbol{n h e A}+$ & Total Food & \% Food & Total Soil & \% Soil & Total Ref. & \% Ref. \\
\hline $3 / 3$ & 4 & 25 & 4 & 100 & 6 & 35.29 \\
\hline $2 / 3$ & 4 & 25 & 0 & 0 & 1 & 5.88 \\
\hline $1 / 3$ & 4 & 25 & 0 & 0 & 2 & 11.76 \\
\hline $0 / 3$ & 4 & 25 & 0 & 0 & 8 & 47.06 \\
\hline & $\mathbf{1 6}$ & $\mathbf{1 0 0}$ & $\mathbf{4}$ & $\mathbf{1 0 0}$ & $\mathbf{1 7}$ & $\mathbf{1 0 0}$ \\
\hline
\end{tabular}

B.

\begin{tabular}{|c|c|c|c|c|c|c|c|}
\hline Sample & $\mathbf{6}$ & $\mathbf{8}$ & $\mathbf{1 4}$ & $\mathbf{1 5}$ & $\mathbf{1 6}$ & $\mathbf{1 7}$ & $\mathbf{1 8}$ \\
\hline S.D. & 0.27 & 0.29 & 0.18 & 0.22 & 0.23 & 0.12 & 0.62 \\
\hline Sample & $\mathbf{2 4}$ & $\mathbf{2 5}$ & $\mathbf{2 6}$ & $\mathbf{2 8}$ & $\mathbf{3 2}$ & $\mathbf{3 7}$ & $\mathbf{4 2}$ \\
\hline S.D. & 0.38 & 0.27 & 0.32 & 0.34 & 0.29 & 0.27 & 0.30 \\
\hline
\end{tabular}

Table 6: A: Number of samples with nheA positive melt peaks three, two, one, and zero times in divisions of food, soil, and reference strains. B: Samples with corresponding $\mathrm{SDs}<1$ when compared against the positive control strain $B$. cereus ATCC 14579 during real-time PCR.

range of the DNA ladder, as shown in Table 4. These bands corresponded to lengths of $1500 \mathrm{bp}, 1200 \mathrm{bp}, 1100 \mathrm{bp}, 1025$ bp, 950 bp, 900 bp, 825 bp, 750 bp, 700 bp, 625 bp, 575 bp, $550 \mathrm{bp}, 450 \mathrm{bp}, 375 \mathrm{bp}, 300 \mathrm{bp}$, and $250 \mathrm{bp}$. Table 7 includes all banding patterns for all nheA positive samples. All other banding patterns were compared against B. cereus reference strain (\#14) and three B. thuringiensis spp. reference strains (\#15-17). All samples were compared against B. cereus, $B$. thuringiensis var. kurstaki, B. thuringiensis var. japonensis, and $B$. thuringiensis var. israelensis. The resulting percent identities of the banding patterns to each reference strain of each sample are recorded in Table 7.

\section{B. cereus (sample \#14)}

Samples 17 and 25 were $6 \%$ identical to the banding pattern of sample 14. Samples 6, 15, 18, 24, and 32 were $13 \%$ identical to sample 14 . Samples 8, 13, 26, and 28 were $19 \%$ identical to sample 14 banding. Samples 16 and 42 were $25 \%$ identical to sample 14, while samples 33 and 35 were $31 \%$ identical. Samples 36 and 37 were $44 \%$ identical to sample 14. No samples were more than $44 \%$ identical to sample 14 .

Nine nhe A negative samples were analyzed using rep-PCR, and include samples 1-5, 7, 9, 11, and 12 (data not shown). Samples 2, 3, 5, and 7 were $6 \%$ identical to the banding 
pattern of sample 14. Samples 1, 4, and 12 were $19 \%$ identical to sample 14 . Sample 11 was $44 \%$ identical to the banding pattern from sample 14 .

\section{B. thuringiensis var. kurstaki (sample \#15)}

When compared against $B$. thuringiensis var. kurstaki, samples $17,24,25$, and 35 shared no identical banding. Samples $8,16,18,26,32,33$, and 36 were $20 \%$ identical to B. thuringiensis var. kurstaki. Samples 6, 13, 14, 28, and 42 were $40 \%$ identical, while sample 37 was $80 \%$ identical to $B$. thuringiensis var. kurstaki.

\section{Table 7.}

\section{B. thuringiensis var. japanensis (sample \#16)}

Samples 6, 17, and 35 shared no identical banding with $B$. thuringiensis var. japanensis, while samples 15 and 18 were $8 \%$ identical. Samples 28 and 32 were $17 \%$ identical to $B$. thuringiensis var. japanensis, but samples $8,13,26$, and 37 were $25 \%$ identical. Samples 14 and 42 were $33 \%$ identical to B. thuringiensis var. japanensis. Samples 24 and 33 were $42 \%$ identical to $B$. thuringiensis var. japanensis banding, while sample 36 was $50 \%$ identical.

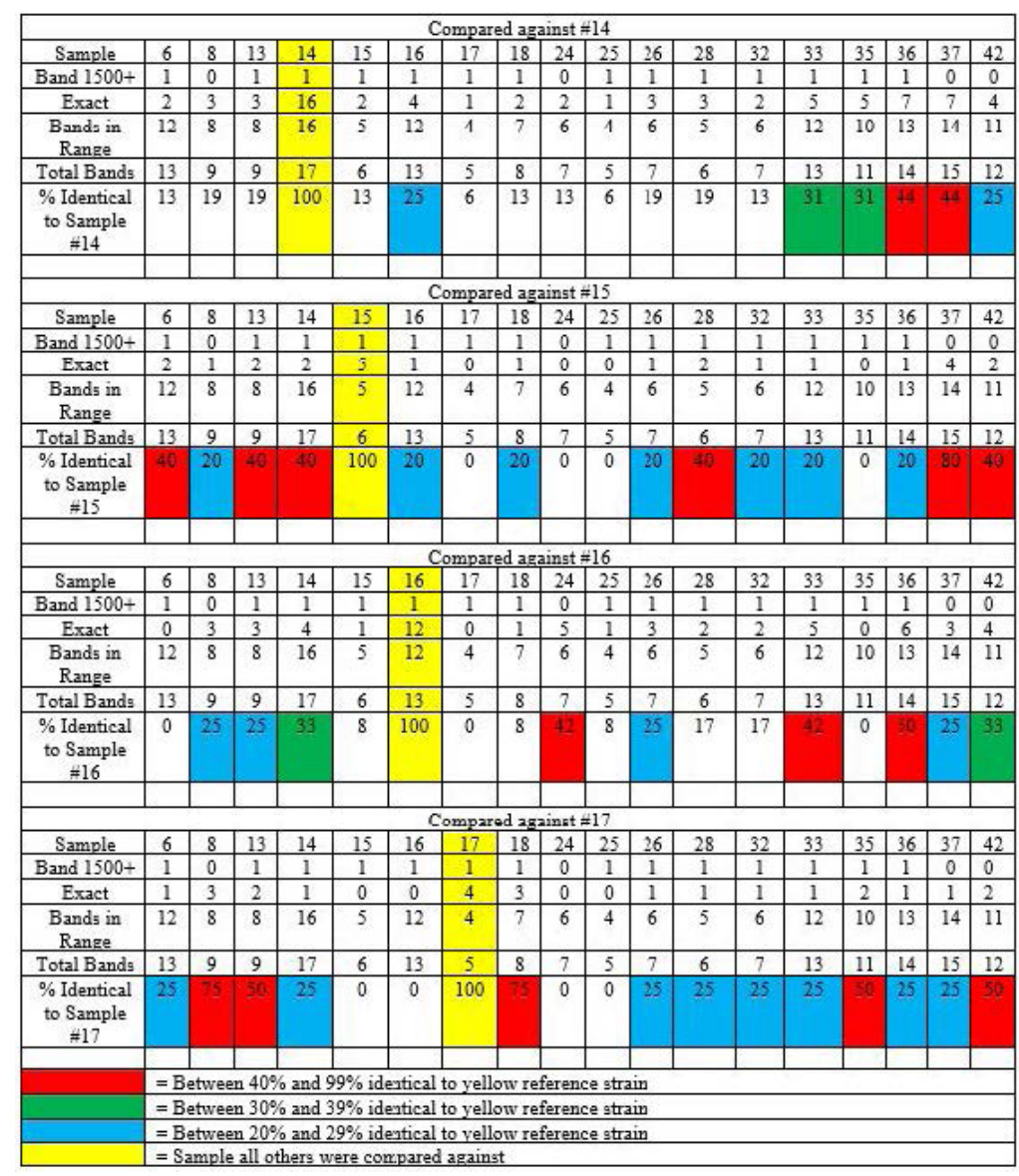

Table 7: Comparison of all rep-PCR banding patterns with B. cereus (sample \#14), B. thuringiensis var. kurstaki (sample \#15), B. thuringiensis var. japanensis (sample \#16), and B. thuringiensis var. israelensis (sample \#17). Yellow cells denote the specific sample all other banding patterns were compared against. Blue cells represent banding patterns $20 \%$ to $29 \%$ identical to each yellow reference strain. Green cells represent banding patterns $30 \%$ to $39 \%$ identical to each yellow reference strain. Red cells represent banding patterns identical banding that was $40 \%$ and above to each yellow reference strain. No samples were more than $44 \%$ identical to B. cereus. Sample 37 was $80 \%$ identical to $B$. thuringiensis var. kurstaki. Sample 36 was $50 \%$ identical to B. thuringiensis var. japonensis. Samples 13, 35, and 42 were $50 \%$ identical to $B$. thuringiensis var. israelensis, while samples 8 and 18 were $75 \%$ identical. 


\section{B. thuringiensis var. israelensis (sample \#17)}

When compared against $B$. thuringiensis var. israelensis, samples 15, 16, 24, and 25 were $0 \%$ identical. Samples 6 , $14,26,28,32,33,36$, and 37 were $25 \%$ identical to $B$. thuringiensis var. israelensis. Samples 13, 35, and 42 were 50\% identical to $B$. thuringiensis var. israelensis, while samples 8 and 18 were $75 \%$ identical.

As shown in Table 5, samples 9, 10, 22, 39, and 43 had one nheA positive amplicon during real-time PCR. Samples 27 and 31 had two nheA positive amplicons late in analysis after initially appearing to only contain one positive melt peak. Consequently, these samples were not subjected to rep-PCR, as the real-time results were inconsistent. Rep-PCR efforts were instead directed at samples that had either three melt peaks or two melt peaks early in analysis within $1 \mathrm{SD}$ of the positive control.

\section{DISCUSSION}

The debate over the ideal method for identification of Bacillus isolates has raged for over 50 years (42). Recent public awareness of potential bioterrorism using the anthrax toxin produced by $B$. anthracis has led government agencies to fund multiple studies aimed at rapidly differentiating $B$. anthracis from other closely related Bacillus species, such as B. cereus and B. thuringiensis. B. anthracis produces the anthrax toxin encoded by two plasmid-based operons, pXO1 and pXO2 $(3,17,42)$. The anthrax toxin primarily kills herbivore mammals but can also kill humans $(42,48)$. Not to be underestimated, $B$. cereus can cause severe food poisoning through its production of emetic and diarrheal toxins $(3,19)$. While heavily used as an insecticidal agent in crops with its Cry crystalline toxins, B. thuringiensis has also recently been demonstrated to cause food poisoning symptoms in humans similar to B. cereus $(3,42)$. Ironically, species like Bacillus coagulans, which was found to contain $n h e A$ at least once in this study, are readily used as probiotics in human health (30). It should be noted that the nhe genes have been among the most common reference virulence genes targeted in PCR-based assays performed in foods, including dairy foods (37). NheA/nheA has thus been widely accepted as an indicator of virulence potential in Bacillus spp. senso lato.

These strains were originally differentiated into species at a time when biologists did not possess the molecular tools to delve deeper than biochemical tests and phenotypical observations (3, 17,42 ). While this strategy worked well for other genera, $16 \mathrm{~S}$ rRNA analysis of differences among $B$. cereus, B. thuringiensis, and $B$. anthracis have shown these species to have a nucleotide sequence difference of < $1 \%$ (48). Thus, the emerging "holy grail" of Bacillus research would be to accurately differentiate these species. Recent advances in molecular biology have allowed scientists to scrutinize the genetic properties of these three "species" (42). After exhaustive studies using DNADNA hybridization, 16S and 23S rRNA comparative analyses, multilocus sequence typing (MLST), fluorescent amplified fragment length polymorphism analysis, rep-PCR, and small nucleotide polymorphism (SNP) analyses, scientists have been unable to reliably differentiate these three Bacillus species.

While many methods have been pursued, most results have suggested that $B$. cereus, $B$. thuringiensis, and $B$. anthracis should be considered the same species due to highly conserved nucleoidal genetic sequences $(3,17,39,43,48)$. Due to the easily identifiable symptoms of $B$. anthracis and B. cereus, there is recent concern among biologists that the "B. anthracis" species may in fact be an oversampled subset of B. cereus (42). Other scientists speculate that $B$. anthracis may have only recently evolved to the point to be considered distinct from $B$. cereus (20). Either way, a separate study confirmed that enough of a difference exists between the genome of $B$. anthracis when compared against $B$. cereus or $B$. thuringiensis to consider $B$. anthracis as identifiable using pulsed-field gel electrophoresis (50).

Of the 45 total food and soil samples in this study, 20 Bacillus isolates were obtained (44.4\%). Twenty-one samples (48.9\%) were not found to contain Bacillus isolates. Three isolates were plated from Jiffy Corn Muffin Mix along with two other samples for a total of $6.7 \%$ after heattreatment but were Gram-positive cocci. Because this research examined Bacillus spp., any non-Gram-positive rod specimens were not analyzed further. 
Bacillus spp. are ubiquitous in nature and form endospores that readily transfer to foods $(3,16,17)$. Initially for the Bacillus isolation approach, nutrient rich BHIB incubation overnight at $32^{\circ} \mathrm{C}$ did not allow for endospore formation. Endospores optimally form when the bacteria are stressed and require 1 to 2 days for full development $(3,36)$. While most samples had already been screened for Bacillus presence, the remaining few were instead shaken for three days at the same conditions to allow sufficient time for endospore formation. Consequently, endospores were better isolated after this change. It is likely that Bacillus spp. endospores were present in many samples that lacked detectable Bacillus isolates initially, like Nestle Nesquik, given their general ubiquity (17). These samples were then subjected to real-time PCR analysis.

There are three nhe genes that are encoded on the nhe $A B C$ operon (3) and have been shown to remain conserved as a cluster during genetic recombination (19). It can reasonably be assumed that the presence of the most proximal subunit of nhe indicates the presence of the other two genes. In the literature, all genes encoding the Nhe and $\mathrm{Hbl}$ enterotoxins have been readily located downstream in both $B$. cereus and B. thuringiensis (35). Of 616 Bacillus isolates tested, none were found to harbor only a single or two of the genes for each operon.

Over three separate real-time PCR runs, all 4 soil samples had three melt peaks within $1 \mathrm{SD}$ of nheA positive $B$. cereus ATCC 14579 . Thus, they were also positive for the presence of the nheA gene. By extension, these strains were also positive for the presence of the nhe $A B C$ operon and could be considered pathogenic. Samples with three melt peaks consistent with the $B$. cereus positive control also resulted in standard deviations much less than 1 , as shown in Table 6B. These melt peaks were extremely similar to each other and to the positive control, meaning that the amplified product was, in fact, nheA.

Of 16 total food isolates, four displayed three nheA positive melt peaks, while four displayed two $n$ he $A$ positive melt peaks. Additionally, 4 food isolates displayed only one nhe $A$ positive melt peak, while four were found to contain no identifiable
nheA genes. Over three real-time PCR runs, samples with three melt peaks within 1 SD of the nheA positive control strain were also considered positive for the presence of nheA. Samples with two of three melt peaks within 1 SD of the positive control strain were also considered to be positive for the presence of $n h e A$, even with an erroneous third melt peak. While real-time PCR is an accurate assay for gene detection, it is still sensitive to pipette error as well as PCR inhibitors (29). Thus, it is likely that user error prevented a third melt peak within 1 SD of the positive control.

Samples with one of three melt peaks within 1 SD of the positive control were treated as potentially positive for the presence of nheA. However, further research of these strains needs to be performed for a definitive answer. One positive melt peak was not determined to be strong enough evidence to ignore two negative results.

After real-time PCR analysis, reference cultures $B$. macerans, B. brevis, B. cereus, B. thuringiensis var. kurstaki, $B$. thuringiensis var. japanensis, and $B$. thuringiensis var. israelensis also displayed three melt peaks within $1 \mathrm{SD}$ of $n$ heA positive $B$. cereus over three runs. Additionally, B. laterosporos displayed two of three total melt peaks consistent with the positive control strain, and by extension contained the nhe $A B C$ operon. The B. thuringiensis and $B$. cereus sample results were expected and confirm earlier work indicating that both are pathogenic $(33,39,48)$. While the reference strains $B$. circulans and B. megaterium were not positive for the presence of $n$ heA in this study, they were found to harbor each $\mathrm{Hbl}$ gene in a separate study (44). It is very possible these strains contained a polymorphic version of nheA.

To the best of our knowledge these samples, minus B. cereus and $B$. thuringiensis, are novel findings that are not usually associated with food pathogenicity $(3,16,17,18)$. However, it is an unsurprising find that Bacillus isolates harboring the nhe $A$ gene were identified in food, at least in $B$. thuringiensis and $B$. cereus. B. cereus and B. thuringiensis are arguably the same species (3) and have been demonstrated to be pathogenic in food (18). There is a general consensus among biologists that most, if not all, Bacillus isolates undergo horizontal gene transfer (17). 
One study determined that of the $B$. cereus and $B$.

thuringiensis isolates obtained from rice, $84.3 \%$ and $100 \%$ of them produced the Nhe enterotoxin, respectively (1). Sixtyone percent and $100 \%$ of these same isolates produced the $\mathrm{Hbl}$ enterotoxin, respectively. A separate study found that of 136 B. cereus isolates obtained from milk, over half were toxic against HeLa cells (10). Additionally, $73.2 \%$ were toxic against HEL cells. A third study noted that of emetic strains identified, $77.5 \%$ of $B$. cereus strains also produced Nhe (27). Yet another study found that the nhe $A B C$ operon was present in every $B$. thuringiensis strain tested (35). The presence of the nhe $A B C$ operon does not necessarily indicate a virulent strain, but has a very high likelihood of expressing these genes in a host environment or in food under permissive conditions $(3,41)$. Thus, future work to determine the pathogenicity of nheA positive samples would include the use of a Tecra VIA immunoassay kit to detect enterotoxin proteins $(3,17,18$, 27). Without this step, the virulence of nheA positive samples cannot be definitively determined.

These data suggest that at least 8 of the 16 isolates from food were positive for the presence of the nhe $A B C$ operon. An additional four food isolates may also be enterotoxigenic, meaning that there is a $75 \%$ chance of any food isolate consumed being potentially enterotoxigenic. Additionally, three reference strains were identified that have not been previously known to harbor enterotoxigenic genes. A large degree of genetic variation exists in nhe sequences among Bacillus spp. (18), giving rise to false negative results in PCRbased detection assays. Strains negative for nheA in real-time PCR have been found to produce the enterotoxin Nhe as determined using a Tecra VIA kit. It is very possible that some of the $n$ heA negative strains from real-time PCR may still be enterotoxigenic due to polymorphism (15).

After real-time PCR analysis, it was necessary to determine how similar the unidentified Bacillus food and soil isolates were to the reference strains $B$. cereus, $B$. thuringiensis var. kurstaki, $B$. thuringiensis var. japanensis, and $B$. thuringiensis var. israelensis using rep- PCR. If banding patterns of the unidentified isolates were very similar to rep-PCR banding patterns of reference strains, then this research would not have identified new strains harboring enterotoxigenic genes.
Within Bacillus, most virulence factors are encoded on plasmids (42), which have been demonstrated to readily transfer between differing species $(3,19)$. Indeed, a recent study indicated that the virulence genes associated with $B$. cereus infection undergo frequent rearrangement both within the bacterial nucleoid and between species (26). Thus, a better method than traditional biochemical tests to detect pathogenic Bacillus strains is to screen for virulence operons present in plasmids or in nucleoidal DNA $(28,42)$. Bacillus genomes that have been sequenced display a high level of genetic synteny in their gene order. Two genes that encode for bacterial ribosomes, $16 \mathrm{~S}$ and $23 \mathrm{~S} \mathrm{rDNA}$, contain genetic sequences that are $<1 \%$ different when compared between $B$. cereus, $B$. thuringiensis, and $B$. anthracis (48). A dissimilarity of $3 \%$ between $16 \mathrm{~S}$ or $23 \mathrm{~S}$ rDNA sequences is the minimal "cut off" between two strains to be considered as distinct species. Additionally, the $g y r B$ gene sequence shared among these species is very homologous (38). Because these genes are shared among different species within the Bacillus genus, they cannot be used to differentiate species $(42,48)$. However, $16 \mathrm{~S}$ and $23 \mathrm{~S}$ rRNA can be used to differentiate between different strains of $B$. anthracis (13). Ultimately, the many attempts at differentiating B. cereus, B. thuringiensis, and $B$. anthracis have led to complete genomic sequencing of 16 strains of these three species (42). This large data pool has allowed Bacillus to serve as a good model for genetic conservation and to allow thorough study of virulence gene transfer. Additionally, the abundance of sequencing information on Bacillus genomes has allowed scientists to statistically differentiate sequencing error from actual polymorphisms.

Interestingly, there are a number of mechanisms that facilitate the movement of genes between different members of the Bacillus genus. One such mechanism is through the natural action of bacteriophage. After lysing its host cell, the bacteriophage will insert its genes into Bacillus genomes. While normally either lytic or lysogenic, it is possible for prophage to undergo random mutation, which renders it unable to enter the lysogenic cycle. In this way, genes from one species of bacteria can be transferred to Bacillus spp. As previously mentioned, Bacillus operons may be on conjugative plasmids. Additionally, Bacillus spp. are naturally competent, allowing these microbes to naturally take up random DNA in their vicinity (19). 
The virulence genes for Whe are present in more strains of Bacillus than is currently accepted within the scientific community. This research identified several "species" of Bacillus that were not previously known to harbor the Nhe enterotoxigenic operon. Given that a debate is currently underway about the very identity of $B$. cereus and other strains, it is improper for food safety experts to screen food products only for B. cereus. Phenotypic-based classification techniques have failed to accurately differentiate Bacillus species. Additionally, no molecular-based approach can accurately differentiate Bacillus (42). The bottom line is the determination of species within Bacillus does not even matter when concerned with food safety. Molecular techniques should instead screen for virulence determinants in microbes instead of identifying said microbes (47). Since endospore formation enables Bacillus spp. to be ubiquitous in the environment and on food, all foods should be examined in this way $(3,16,36)$. This is the only true way to determine whether food products are safe for human consumption. 
1. Ankolekar, C., Rahmati, T., and Labbe, R.G. 2009. Detection of toxigenic Bacillus cereus and Bacillus thuringiensis spores in U.S. rice. International Journal of Food Microbiology. 128: 460-66.

2. Antwerpen, M., Ximmermann, P., Bewley, K., Frangoulidis, D., and Meyer, H. 2008. Real-time PCR system targeting a chromosomal marker specific for Bacillus anthracis. Molecular and Cellular Probes. 22: 313-15.

3. Arnesen, L., P. Stenfors, A. Fagerlund, and P.E. Granum. 2008. From soil to gut: Bacillus cereus and its food poisoning toxins. FEMS Microbiol. Rev. 32:579-606.

4. Bottone, E.J. 2010. Bacillus cereus as a volatile human pathogen. Clin. Microbiol. Rev. 23:382-398.

5. Brousseau, R., A. Saint-Onge., G. Prefontaine, L. Masson, and J. Cabana, 1993. Arbitrary polymerase chain reaction, a powerful method to identify Bacillus thuringiensis serovars and strains. Appl. Environ. Microbiol. 59:114-19.

6. Cardazzo, B., Negrisolo, E., Carraro, L. Alberghini, L., Patarnello, T., and Ciaccone, V. 2008. Multiple- locus sequence typing and analysis of toxin genes in Bacillus cereus food-borne isolates. Appl. Environ. Microbiol. 74:850-860.

7. Chen, M.L. and H.Y. Tsen. 2002. Discrimination of Bacillus cereus and Bacillus thuringiensis with 16s rRNA and gyrB gene-based PCR primers and sequencing of their annealing sites. J. Appl. Microbiol. 92: 912-19.

8. Cherif, A., Brusetti, L., Borin, S., Rizzi, A., Boudabous, A., Khyami-Horani, H., and Daffonchio, D. 2003. Genetic relationship in the 'Bacillus cereus group' by rep-PCR fingerprinting and sequencing of a Bacillus anthracis-specific repPCR fragment. J. Appl. Microbiol. 94:1108-19.

9. Cherif, A., Ettoumi, B., Raddadi, N., Daffonchio, D., and Boudabous, A. 2007. Genomic diversity and relationship of Bacillus thuringiensis and Bacillus cereus by multi-REP-PCR fingerprinting. Can. J. Microbiol. 53: 343-50.

10. Christiansson, A., Naidu, A.S., Nilsson, I., Wadstrom, T., and Pettersson, H.E. 1989. Toxin production by Bacillus cereus dairy isolates in milk at low temperatures. Applied and Environmental Microbiology. 55: 2595-2600.

11. Cooper, R.M. and J.L. McKillip. 2006. Enterotoxigenic Bacillus spp. DNA fingerprint revealed in naturally contaminated nonfat dry milk powder using rep-PCR. J. Basic Microbiol. 46:358-64.

12. Cummings, C.A., Bormann Chung, C.A., Fang, R., Barker, M., Brzoska, P.M., Williamson, P., Beaudry, J.A., Matthews, M., Schupp, J.M., Wagner, D.M., Furtado, M.R., Keim, P., and Budowle, B. 2009. Whole-genome typing of Bacillus anthracis isolates by next-generation sequencing accurately and rapidly identifies strain-specific diagnostic polymorphisms. Forensic Sci. Intl. 2:300-301.

13. Daffonchio, D., Raddadi, N., Merabishvili, M., Cherif, A., Carmagnola, L., Brusetti, L., Rizzi, A., Chanishvili, N., Visca, P., Sharp, R., and Borin, S. 2006. Strategy for identification of Bacillus cereus and Bacillus thuringiensis strains closely related to Bacillus anthracis. Applied and Environmental Microbiology. 72: 1295-1301.

14. Didelot, X., Barker, M., Falush, D., and Priest, F.G. 2009. Evolution of pathogenicity in the Bacillus cereus group. Systematic and Applied Microbiology. 32: 81-90.

15. Ehling-Schulz, M., Guinebretiere, M.H., Monthan, A., Berge, O., Fricker, M. and Svensson, B. 2006. Toxin gene profiling of enterotoxic and emetic Bacillus cereus. FEMS Microbiol Lett. 260: 232-40. 
16. Giffel, M.C. and R.R. Beumer. 1999. Bacillus cereus: a review. The Journal of Food Technology in Africa. 4: 7-13.

17. Griffiths, M.W. 2010. Pathogens and toxins in foods: challenges and interventions. ASM Press, Washington, DC. pp. $1-19$.

18. Hansen, B.M. and N.B. Hendriksen. 2001. Detection of enterotoxic Bacillus cereus and Bacillus thuringiensis strains by PCR analysis. Appl. Environ. Microbiol. 67:185-89.

19. Helgason, E., Okstad, O.A., Caugant, D.A., Johansen, H.A., Fouet, A., Mock, M., Hegna, I., and Kolsto, A.B. 2000. Bacillus anthracis, Bacillus cereus, and Bacillus thuringiensis - one species on the basis of genetic evidence. Appl. Environ. Microbiol. 66:2627-2630.

20. Henerson, I., Duggleby, C.J., and Turnbull, P.C.B. 1994. Differentiation of Bacillus anthracis from other Bacillus cereus group bacteria with the PCR. Int. J. Syst. Bacteriol. 44:99-105.

21. Hoffmaster, A.R., Novak, R.T., Marston, C.K., Gee, J.E., Helsel, L., Pruckler, J.M., and Wilkins, P.P. 2008. Genetic diversity of clinical isolates of Bacillus cereus using multilocus sequence typing. BMC Microbiol. 8:191. doi: 10.1186/1471$2180 / 8 / 191$.

22. Hong, H.A., To, E., Fakhry, S., Baccigalupi, L., Ricca, E., and Cutting, S.M. 2009. Defining the natural habitat of Bacillus spore formers. Res. Microbiol. 160:375-379.

23. Jackson, P.J., Hill, K.K., Laker, M.T., Ticknor, M.T., and Keim, P. 1999. Genetic comparison of Bacillus anthracis and its close relatives using amplified fragment length polymorphism and polymerase chain reaction analysis. Journal of Applied Microbiology. 87: 263-9.

24. Jersek, B., Gilot, P., Gubina, M., Klun, N., Mehle, J., Tcherneva, E., Rijpens, N., and Herman, L. 1999. Typing of Listeria monocytongenes strains by repetitive element sequence-based PCR. Journal of Clinical Microbiology. 37: 103-9.

25. Jolley, K.A., Chan, M.S., and Maiden, M.C.J. 2004. mlstdbNet - distributed multi-locus sequence typing (MLST) databases. BMC Bioinformatics 5:86-93.

26. Kim, Y.R. and Batt, C.A. 2008. Riboprint and virulence gene patterns for Bacillus cereus and related species. J. Microbiol. Biotechnol. 18: 1146-55.

27. Kim, J.B., Kim, J.M., Kim, S.Y., Kim, J.H., Park, Y,B., Choi, N.J., and Oh, D.H. 2010. Comparison of enterotoxin production and phenotypic characteristics between emetic and enterotoxic Bacillus cereus. Journal of Food Protection. 73:1219-24.

28. Klee, S.R., Nattermann, H., Becker, S., Urban-Schriefer, M., Franz, T., Jacob, D., and Appel, B. 2006. Evaluation of different methods to discriminate Bacillus anthracis from other bacteria of the Bacillus cereus group. Journal of Applied Microbiology. 100: 673-81.

29. Lauri, A. and P.O. Mariana. 2009. Potentials and limitations of molecular diagnostic methods in food safety. Genes Nutr. 4: $1-12$.

30. Maity, T.K. and A.K. Misra. 2009. Probiotics and human health: synoptic review. African Journal of Food Agriculture Nutrition and Development. 9. 
31. Manzano, M, Cocolin, L., Carlo Cantoni, and Comi, G. 2003. Bacillus cereus, Bacillus thuringiensis and Bacillus mycoides differentiation using a PCR-RE technique. International Journal of Food Microbiology. 81: 249-54.

32. Marchuk, D., Drumm, B., Saulino, A., and Collins, F.S. 1990. Construction of T-vectors, a rapid and general system for direct cloning of unmodified PCR products. Nucleic Acids Research. 19: 1154.

33. McKillip, J.L. 2000. Prevalence and expression of enterotoxins in Bacillus cereus and other Bacillus spp., a literature review. Antonie Van Leeuwenhoek. 77: 393-9.

34. McKillip, J.L. and M.A. Drake. 2005. Genetic-based methods for detection of bacterial pathogens. Pp. 187-1-187-12. In (Y.H. Hui, Ed.) Handbook of Food Science and Technology, vol. 4. CRC Press, Boca Raton, FL.

35. Ngamwongsatit, P., Buasri, W., Pianariyanon, P., Pulsrikarn, C., Ohba, M., Assavanig, A., and Panbangred, W. 2008. Broad distribution of enterotoxin genes (HBLCDA, NHEABC, cytK, and entFM) among Bacillus thuringiensis and Bacillus cereus as shown by novel primers. International Journal of Food Microbiology. 121: 352-56.

36. Nicholson, W.L., Munakata, N., Horneck, G., Melosh, H.J., and Setlow, P. 2000. Resistance of Bacillus endospores to extreme terrestrial and extraterrestrial environments. Microbiology and Molecular Biology Reviews. 64: 548-72.

37. Owusu-Kwarteng, J., Wuni, A., Akabanda, F., Tano-Debrah, K., and Jespersen, L. 2017. Prevalence, virulence factor genes and antibiotic resistance of Bacillus cereus sensu lato isolated from dairy farms and traditional dairy products. BMC Microbiol. 17:65. DOI 10.1186/s12866-017-0975-9

38. Park, S.H., Kim, H.J., Kim, J.H., Kim, T.W., and Kim, H.Y. 2007. Detection and identification of Bacillus cereus group bacteria using multiplex PCR. Journal of Microbiology and Biotechnology. 17: 1177-82.

39. Peruca, A.P.S., G.T. Vilas-Boas, and O.M.N. Arantes. 2008. Genetic relationships between sympatric populations of Bacillus cereus and Bacillus thuringiensis, as revealed by rep-PCR genomic fingerprinting. Mem Inst Oswaldo Cruz. 103: 497-500.

40. Phelps, R.J. and McKillip, J.L. 2002. Enterotoxin production in natural isolates of Bacillaceae outside the Bacillus cereus group. Applied and Environmental Microbiology. 68: 3147-51.

41. Rahmati, T. and Labbe, R. 2008. Levels and toxigenicity of Bacillus cereus and Clostridium perfringens from retail seafood. Journal of Food Protection. 71: 1178-85.

42. Rasko, D.A., Altherr, M.R., Han, C.S., and Ravel, J. 2005. Genomics of the Bacillus cereus group of organisms. FEMS Microbiology Reviews. 29: 303-29.

43. Reyes-Ramirez, A. and Ibarra, J.E. 2005. Fingerprinting of Bacillus thuringiensis type strains and isolates by using Bacillus cereus group-specific repetitive extragenic palindromic sequence-based PCR analysis. Applied and Environmental Microbiology. 71: 1346-55.

44. Rowan, N.J., Caldow, G., Gemmell, C.G., and Hunter, I.S. 2003. Production of diarrheal enterotoxins and other potential virulence factors by veterinary isolates of Bacillus species associated with nongastrointestinal infections. Applied and Environmental Microbiology. 69: 2372-76.

45. Schoeni, J.L. and Amy C. Lee Wong. 2004. Bacillus cereus food poisoning and its toxins. Journal of Food Protection. 68: 636-48. 
46. Travers, R., S., Martin, P.A.W., and Reichelderfer, C.F. 1987. Selective process for efficient isolation of soil Bacillus spp. Appl. Environ. Microbiol. 53:1263-66.

47. Vilas-Boas, G., Sanchis, V., Lereclus, D., Lemos, M.V.F., and Bourguet, D. 2002. Genetic differentiation between sympatric populations of Bacillus cereus and Bacillus thuringiensis. Applied and Environmental Microbiology. 68: 1414-24.

48. Vilas-Boas, G.T., A.P.S. Peruca, and O.M.N. Arantes. 2007. Biology and taxonomy of Bacillus cereus, Bacillus anthracis, and Bacillus thuringiensis. Can. J. Microbiol. 53:673-87.

49. Wilson, M.K., Vergis, J.M., Alem, F., Palmer, J.R., Keane-Myers, A.M., Brahmbhatt, T.N., Ventura, C.L., and O’Brien, A.D. 2011. Bacillus cereus G9241 makes anthrax toxin and capsule like highly virulent $B$. anthracis Ames but behaves like attenuated toxigenic nonencapsulated B. anthracis sterne in rabbits and mice. Infec. Immun. 79:301203019.

50. Zhong, Y.S., Yoshida, T.M., and Marrone, B.M. 2007. Differentiation of Bacillus anthracis, Bacillus cereus and Bacillus thuringiensis by using pulsed-field gel electrophoresis. Applied and Environmental Biology. 73: 3446-49.

51. Zwick, M.E., J. Sandeep, X. Didelot, P.E. Chen, K.A. Bishop-Lilly, A.C. Stewart, K. Willner, S. Lentz,

52. N. Nolan, M.K. Thomason, S. Sozhammannan, A.J. Mateczun, L. Du, and T.D. Read. 2012. Genomic characterization of the Bacillus cereus sensu lato species: backdrop to the evolution of Bacillus anthracis. Genome Res. doi: 10.1101/ gr.134437.111. 